Derecho civil 


\section{El precio determinado por tercero en el Código Civil peruano}

\section{César Arturo Ayllón Valdivia}

La justicia es la primera virtud de las instituciones sociales, como la verdad lo es de los sistemas de pensamiento. Una teoría, por muy atractiva, elocuente y concisa que sea, tiene que ser rechazada o revisada si no es verdadera; de igual modo, no importa que las instituciones estén ordenadas y sean eficientes: si no son justas han de ser reformadas y abolidas.”

Cuando las partes contratantes deciden dejar la determinación del precio al arbitrio de un tercero, nos encontramos ante un dilema del derecho, cual es determinar la razón por la que debería prevalecer dicha decisión, conforme a su buen criterio y conocimiento, o darle la razón a quien argumenta que aquella decisión es arbitraria e injusta, toda vez que no coincide con lo que se establece normalmente en el mercado.

Si bien nos encontramos ante una institución ampliamente tratada en la doctrina jurídica y cuyos fundamentos revisten singular importancia para nuestra sociedad, al igual que muchas de las instituciones del Código Civil, los verdaderos alcances del precio determinado por tercero resultan aún de difícil comprensión.

Motivados por lo controversial del tema, analizaremos esta institución jurídica a partir de los más recientes estudios del análisis económico y del derecho civil patrimonial.

RAWLS, John. Teoría de la justicia. México D.F.: Fondo de Cultura Económica, 1999, p. 17. 


\section{La definición jurídica del precio}

A continuación veremos algunas de las concepciones jurídicas que ha ensayado la doctrina jurídica para definir lo que es el precio.

Wayar define el precio como "la cantidad de dinero que el comprador está obligado a pagar al vendedor como contraprestación por la transferencia de la propiedad de la cosa que aquel recibe". ${ }^{1}$

En opinión de Planiol, "el precio es la suma de dinero que el comprador se obliga a dar a cambio de la cosa". ${ }^{2}$

Por su parte, Sánchez Román considera que "por precio se entiende la cantidad o el valor pecuniario en que se estima una cosa. Constituye un requisito esencial de la compra-venta". ${ }^{3}$

Bonnecasse piensa que "si la obligación del vendedor recae sobre una cosa, la del comprador recae sobre una suma de dinero, llamada precio". ${ }^{4}$

Los Mazeaud consideran que "el precio consiste necesaria y únicamente en una suma de dinero que el comprador se obliga a entregarle al vendedor". ${ }^{5}$

Según Gasca, el precio es "la cantidad de moneda que se cambia por una cosa". ${ }^{6}$

Colin y Capitant sostienen que el precio es "la cantidad de dinero que el comprador se obliga a pagar al vendedor".?

1 WAYAR, Ernesto. Compraventa y permuta. Buenos Aires: Editorial Astrea, 1984, p. 249.

2 Citado por CASTILLO FREYRE, Mario. El precio en el contrato de compraventa y permuta. Lima: Fondo Editorial de la Pontificia Universidad Católica del Perú, 1996, p. 31.

3 Íd., op. cit.

4 BONNECASE, Julien. Elementos de derecho civil. Tomo II. Puebla: Biblioteca Jurídico Sociológica, 1945, p. 529.

5 MAZEAUD, Henri, León y Jean. Tratado de derecho civil. Parte III, volumen III. Buenos Aires: Ediciones Jurídicas Europa-América, 1959, p. 138.

6 GASCA, C.L. Compraventa civil y comercial. Tomo I. Madrid: Revista de Derecho Privado, 1931, p. 542.

7 Citado por BADENES GASSET, Ramón. El contrato de compraventa. Tomo I. Buenos Aires: Librería Bosch, 1979, p. 153. 
$\mathrm{Al}$ parecer de Gómez Estrada, "el precio constituye uno de los elementos esenciales del contrato de venta, de suerte que si él falta no hay contrato o degenera en uno distinto. Precio, dice el artículo 1849, es 'El dinero que el comprador da por la cosa vendida'...". ${ }^{8}$

León Barandiarán opina que "el precio es, pues, la fijación convencional de un valor económico atribuido a la cosa. El comprador al pagar el precio, o sea, la respectiva cantidad pecuaniaria, realiza también una transferencia domínica, desde que el vendedor viene a ser dueño de dicho dinero". 9

Castillo Freyre comenta que es "el objeto de la principal prestación del comprador en un contrato de compraventa, consistente en transferir la propiedad de - fundamentalmente - dinero, o signo que lo represente, a cambio de la obligación del vendedor de transferir la propiedad de uno o más bienes". ${ }^{10}$

Rezzónico define el precio como "la contraprestación que efectúa el comprador, por la cosa que el vendedor le entrega en propiedad". ${ }^{11}$

Para la Real Academia Española, el precio es "el valor pecuniario en que se estima una cosa" (sin lugar a dudas, esta es una definición muy amplia). ${ }^{12}$

Rubino considera que el precio es "la contraprestación equivalente (correspectivo) al derecho transferido".$^{13}$

Como se observa, las definiciones del precio están relacionadas, básicamente, con la prestación en dinero que debe entregar el comprador en el caso de un contrato de compraventa. Algunos, incluso, afirman que

8 GÓMEZ ESTRADA, César. De los principales contratos. 3. ${ }^{a}$ edición. Bogotá: Editorial Temis S.A., 1996, p. 29.

9 LEÓN BARANDIARÁN, José. Contratos en el derecho civil peruano. Tomo I. Lima: Universidad Nacional Mayor de San Marcos, 1965, p. 16.

10 CASTILLO FREYRE, Mario. Op. cit., p. 33.

11 REZZÓNICO, Luis María. Estudio de contratos en nuestro derecho civil. Buenos Aires: Ediciones Depalma, 1967, p. 153.

12 REAL ACADEMIA ESPAÑOLA. Diccionario. Tomo II, p. 1095.

13 Citado por BADENES GASSET, Ramón. Op. cit., p. 188. 
tal prestación debe ser equivalente al valor del bien que entrega el vendedor.

\section{La definición económica del precio}

Descrita la definición jurídica del precio conforme a la doctrina jurídica en general, veamos enseguida su definición económica desde el punto de vista de la doctrina económica, definición que a lo largo de la historia ha sido ampliamente tratada por un sinnúmero de estudiosos desde las más variadas posiciones filosóficas, teológicas, sociológicas, antropológicas, éticas, entre otras. Dentro de esta gran mixtura de opiniones e ideologías escogimos, como base de estudio, la más moderna doctrina económica mayoritaria, concebida con el nombre de teoría subjetiva del valor. ${ }^{14}$

A este respecto, resulta fundamental comprender la distinción entre valor de uso y valor de cambio, para entender la manera como se llegan a establecer los precios. Este problema fue planteado por primera vez

14 Para esta parte recurrimos a la siguiente bibliografía: LEKACHMAN, Robert. Historia de las doctrinas económicas. Buenos Aires: Editorial Víctor Lerú S.R.L., 1962; LANDRETH, Harry y David C. COLANDER. Historia del pensamiento económico. México D.F.: Editorial CECSA, 1998; BARBER, William J. Historia del pensamiento económico. Madrid: Alianza Editorial, 1970; FRIEDMAN, Milton. Teoría de los precios. Chicago: Editorial Alianza, 1962; MEINER, Roger E. y Robert MILLER. Microeconomía. 3. a edición. México D.F.: McGraw-Hill, pp. 3-98; POSNER, Richard. El análisis económico del derecho. México D.F.: Fondo de Cultura Económica, 1998, pp. 11-33; PINDYCK, Robert S. Microeconomía. 4. ${ }^{a}$ edición. Madrid: Prentice Hall, 1998; QUIRK, James P. Microeconomía. Barcelona: Antoni Bosh, 1998, pp. 3-21; LLOYD, Reynolds G. Principios de microeconomía. Barcelona: El Ateneo, 1997; MACHÓN MORCILLO, Francisco. Principios de economía. Madrid: McGraw-Hill, 1996, pp. 3-51; GONZALES FABRE, Raúl. Justicia en el mercado. Caracas: UCAB, 1998; COOTER, Robert y Tomas ULEN. Derecho y economía. México D.F.: Fondo de Cultura Económica, 1998; CASSEL, Gustavo. Economía social teórica. Madrid: Editorial Aguilar, 1960, pp. 147-205; JAMES, Emile. Historia del pensamiento económico. Madrid: Editorial Aguilar, 1963, pp. 21248; DENIS, Henri. Historia del pensamiento económico. Barcelona: Editorial Ariel, 1970, pp. 155-436; entre otros. 
por el padre de la economía, Adam Smith, a través de "la paradoja del agua y el diamante". Dicho economista indicaba que nada es más útil que el agua, pero que con ella difícilmente podría comprarse algo, o que muy pocas cosas podrían intercambiarse con ella. Por el contrario, un diamante, con dificultad, posee un valor de uso, pero con frecuencia puede intercambiarse con él una gran cantidad de bienes. Los teóricos clásicos no pudieron resolver este dilema porque pensaban en términos de la utilidad total que el agua y los diamantes proporcionaban a los consumidores y no comprendían la importancia de la utilidad marginal. Los economistas marginalistas, en cambio, propusieron que no es la utilidad total de un bien lo que ayuda a averiguar su valor de cambio, sino la utilidad de la última unidad consumida. Así por ejemplo, el agua es por cierto útil, necesaria para la vida, pero como es relativamente abundante, el consumo de un vaso más irá disminuyendo hasta tener un valor relativamente bajo. Los marginalistas redefinieron el concepto de valor de uso sustituyendo la idea de la utilidad total por la idea de utilidad marginal o adicional, es decir, la utilidad de una unidad adicional de un bien. ${ }^{15}$

Así se logra explicar la razón por la cual un mismo bien puede llegar a tener distintos precios o valores de intercambio, sin que ello signifique negar su valor de uso. Las personas son las que determinan el precio de cada una de sus transacciones de manera absolutamente subjetiva. El precio está relacionado con el valor marginal de un bien, es decir, con el valor de una cantidad adicional del bien. Así por ejemplo, el agua tiene un precio bajo, no porque su "valor de uso" sea bajo - pues evidentemente es alto, ya que no podríamos vivir sin ella -, sino porque su valor marginal, es decir, lo que estaríamos dispuestos a pagar para poder beber un vaso más, es bajo.

El intercambio es una actividad económica dirigida a obtener el máximo beneficio con los medios disponibles, y obedece a la existencia de diferencias en las valuaciones subjetivas que de los mismos bienes hacen los individuos. El intercambio sólo podrá tener lugar cuando sea ventajoso para las dos partes, cuando cada cual obtenga subjetivamente más de lo

15 Que tiene entre sus más importantes representantes a los marginalistas: Gossen, Jevons, Menger y Walras. 
que da. Así por ejemplo: $\mathrm{Si}$ "A" da a una unidad de " $\mathrm{A}$ " mayor valor que a una de " $y$ ", $y$ " $B$ " da a una unidad de " $y$ " mayor valor que a una de " $x$ ", entonces el intercambio será posible. Por ello, el primer intercambio de una porción de " $\mathrm{x}$ " por una porción de " $\mathrm{y}$ " es muy ventajoso para ambas partes. El segundo intercambio ya lo será menos, puesto que ambas partes le atribuirán un menor valor a lo que reciben y algo más a lo que dan. La relación entre los valores subjetivos de las mercancías para cada individuo se modificará hasta que sea igual para ambos. En este punto cesará el intercambio, pues no habrá incentivo para continuarlo. ${ }^{16}$

El precio, así, revela las valorizaciones subjetivas de las partes contratantes. Si alguien pagó un precio por algo es porque lo valoriza en más de lo que pagó, y si alguien estuvo dispuesto a venderlo es porque lo valoriza en menos del precio pactado.

Veamos un ejemplo en un mercado imaginario donde existen tres compradores que desean una misma silla de distinta manera. "C1" la valora en $\$ 10$, "C2" en $\$ 15$, “C 3 " en $\$ 20$, y el vendedor "V1" la valora en $\$ 15$. Conforme a las reglas de la economía de mercado, "V1" no transferiría su silla a favor de "C1", pues perdería $\$ 5$, y tampoco lo haría a favor de "C2", ya que "V1" valora su bien en $\$ 15$ y le daría lo mismo tener la silla o $\$ 15$, por lo que si se le ofrece esa suma, al no obtener ninguna ganancia, no incurriría en la molestia de efectuar el cambio. Solo si el precio es superior a $\$ 15$ hay un vendedor y un comprador. En nuestro ejemplo, la única posibilidad que resulta beneficiosa para "V1" es la que le ofrece " $\mathrm{C} 3$ ", por lo que el precio se fijará en algún punto entre el límite superior marcado por el comprador efectivo (C3) y el límite inferior marcado por el vendedor efectivo (V1). ${ }^{17}$

16 A este respecto, cabe precisar que Adam Smith había exhumado de la literatura anterior la vieja paradoja del diamante-agua: los diamantes tienen un precio elevado, pero son de poca utilidad, en tanto que el agua tiene un precio bajo, pero tiene una gran utilidad. Los teóricos clásicos no pudieron resolver esta paradoja porque pensaban en términos de la utilidad total que el agua y los diamantes proporcionaban a los consumidores, y no comprendían la importancia de la utilidad marginal. ROLL, Eric. Historia de las doctrinas económicas. Tomo I. México D.F.: Fondo de Cultura Económica, 1942, p. 357.

17 Ver BENEGAS LYNCH, Alberto. Op. cit., pp. 21-112. 
De esta manera se puede explicar la razón por la que un mismo bien puede llegar a tener distintos precios o valores de intercambio, sin que ello signifique negar su valor de uso. Las personas son las que determinan el precio de cada una de sus transacciones de manera absolutamente subjetiva. Al respecto, debe recordarse que según el principio del costo-beneficio, cada persona buscará realizar una actividad si y solo si los beneficios que espera son superiores; sin embargo, dichos beneficios tenderán a ser decrecientes a medida que se obtenga una unidad más de la misma cosa. ${ }^{18}$ Asimismo, en cuanto al principio del costo de oportunidad, vimos que al optar por una alternativa sacrificando varias opciones, el costo de oportunidad venía a estar dado por la mejor de las opciones que dejamos de lado por obtener lo que buscamos. ${ }^{19}$

18 Así por ejemplo, si estamos sentados cómodamente, escuchando un disco antiguo, y de pronto nos damos cuenta de que las canciones que vienen no son de nuestro agrado, es en ese momento que decidiremos entre levantarnos y saltar esas canciones o quedarnos quietos. El beneficio será evitar las canciones que no nos gustan, y el costo será la molestia de levantarnos de la silla. Si estamos cómodos y la música no es muy molesta, probablemente no nos levantaremos; pero si es muy molesta, seguramente sí lo haremos. Según los economistas, aun en decisiones muy sencillas como estas es posible expresar los costos y beneficios relevantes en términos monetarios. Entonces, si consideráramos el costo de levantarnos de la silla, encontraríamos que si a una persona de clase media le ofrecen un céntimo de sol por levantarse, probablemente no lo aceptaría, pero si le ofrecen cien soles, seguramente lo haría de inmediato. Aunque, evidentemente, habrá un precio mínimo por el cual estaríamos dispuestos a levantarnos de la silla. FRANK, Robert H. Microeconomía y conducta. Madrid: McGraw-Hill, 1992, pp. 5 y 6.

19 Así por ejemplo, si una persona nos pregunta cuánto cuesta ir al cine, no podríamos darle una respuesta completa, pues, en primer lugar, el coste no es tanto la " $x$ " cantidad de dinero que tenemos que pagar por la entrada al cine, sino las otras cosas que podríamos comprar con dicha cantidad. Por otra parte, nuestro tiempo es un recurso escaso que debe figurar en dicho cálculo. Tanto el dinero como el tiempo representan oportunidades perdidas por ir al cine, o lo que los economistas denominan "coste de oportunidad". Destinar un recurso a un fin significa no poder destinarlo a otro; por lo tanto, cuando pensamos destinar un recurso cualquiera a un fin, debemos considerar el siguiente mejor uso que hubiéramos podido darle. Este siguiente mejor uso es la medida formal del costo de oportunidad. PINDYCK, Robert S. y Daniel L. RUBINFELD. Microeconomía. 4. edición. Madrid: Prentice Hall, 1998, p. 56. 
Por otra parte, la racionalidad de los agentes que interactúan en el mercado es un problema fundamental de la teoría económica debido a su complejidad. No existe un modelo de racionalidad aplicable a todas las personas; cada cual actúa de acuerdo con distintas motivaciones que escapan a una regla general. No es posible, entonces, establecer un criterio objetivo para determinar quién es irracional o racional a la hora de tomar decisiones económicas, pues la mayor parte de las veces, por las deficiencias del mercado - como lo es la falta de información -, decidimos de manera intuitiva. ${ }^{20}$

\section{El precio determinable}

Los contratos con precio determinable son aquellos que carecen de uno inicial y se encuentran sometidos a una fase peculiar pendiente pretio, distinta de las situaciones de pendencia propias de la condición y el término, y que se puede reconstruir a partir de ellas.

Teniendo en cuenta que la pendencia del precio determinable está provocada por un certus an, incertus quando, incertus quantum, y no se presume establecida a favor de ningún contratante, como más bien en perjuicio de todos ellos, esta situación se podrá calificar como una pendencia de la obligación de pagar el precio en cuanto a sus efectos definitivos.

20 Así por ejemplo, Herbert Simon fue el primero en decir que los seres humanos son incapaces de comportarse como los seres racionales que describen los modelos convencionales de la elección racional. Como pionero de la inteligencia artificial, llega a esta conclusión justamente cuando trataba de enseñar a una computadora a razonar un problema. Simon descubre que cuando nos encontramos ante un enigma, raras veces llegamos a una solución clara y lineal; más bien buscamos, de una manera casual, hechos e información potencialmente relevantes, y normalmente desistimos cuando logramos un umbral que, supuestamente, resuelve el problema, por lo que las conclusiones generalmente son incoherentes e incluso incorrectas. Pese a ello, las soluciones a las que arribamos nos son útiles, aunque imperfectas. En palabras de Simon, somos "satisfacedores", no maximizadores. FERNÁNDEZ BACA, José. Microeconomía: teoría y aplicaciones. Volumen I. Lima: Universidad del Pacífico, 2000, pp. 259 y 260 . 
Aparte de eso, el contrato y la misma obligación de pagar tienen una cierta exigibilidad provisional: se encuentran especialmente sometidos a las obligaciones derivadas de la buena fe; no están sometidos a pendencia la obligación de entregar la cosa ni los efectos reales que se derivan de ella; debe descartarse que el precio determinable suponga un régimen especial en cuanto a los riesgos de la cosa vendida; y no cabe instar la resolución por impago del precio mientras este sea desconocido, pero sí por cualquier motivo.

$\mathrm{Al}$ respecto, Muñoz nos dice que "el contrato de compraventa es perfecto, válido y eficaz, cuando en él se indica un criterio seguro para la determinación del precio, por ejemplo precio de lista, etc. Empero, si el criterio para la fijación no es seguro, la venta no será perfecta" ${ }^{21}$

Peirano, por su parte, opina que "el objeto del contrato puede ser determinado o determinable (artículo 1283 del código civil, que señala que 'la cantidad puede ser incierta con tal que el contrato fije las reglas o contenga datos que sirvan para determinarla')" ${ }^{22}$

Roberto de Ruggiero considera que "el precio debe ser cierto y determinado, o, por lo menos, debe el contrato contener los elementos necesarios para su determinación...". ${ }^{23}$

Piensan Ripert y Boulanger que "no existe venta mientras no haya un precio fijado. Pero basta que el precio sea determinable por vía de relación directa con elementos que no dependan de la voluntad de las partes". ${ }^{24}$

De la Puente y Lavalle sostiene que "el precio es determinado cuando no ha sido objetivamente fijado el monto, pero se han fijado criterios

${ }^{21}$ MUÑOZ, Luis. Contratos. Tomo II. Buenos Aires: Tipográfica Editora Argentina, 1960, p. 304.

22 PEIRANO FACIO, Jorge y Gustavo ORDOQUI CASTILLO. Contratos. Montevideo: Ediciones del Foro S.R.L., 1997, p. 278.

23 DE RUGGIERO, Roberto. Instituciones del derecho civil. Tomo II, volumen II. Madrid: Instituto Editorial Reus, 1944, p. 336.

${ }^{24}$ RIPERT, Georges y Jean BOULANGER. Tratado de derecho civil. Según el tratado de Planiol, tomo VIII. Buenos Aires: La Ley, 1971, p. 39. 
y referencias que permiten establecerlo con certeza, sin influencia posible de la voluntad posterior de las partes". ${ }^{25}$

A este respecto, cabe recordar que la doctrina mayoritaria considera que la compraventa es un contrato esencialmente conmutativo. Sin embargo, acerca de este concepto existirían dos corrientes doctrinarias.

La primera relaciona la aleatoriedad con la pérdida o beneficio económico que las partes pueden obtener de su transacción. Esta posición está representada por Planiol y Ripert, quienes sostienen:

Esta distinción no es sino una subdivisión de los contratos a título oneroso. El contrato oneroso es conmutativo, cuando la extensión de las prestaciones que se deben las partes es inmediatamente cierta, de manera tal que cada una de ellas puede apreciar de inmediato el beneficio o la pérdida que le causa el contrato; es aleatorio cuando la prestación debida por una de las partes depende de un acontecimiento incierto, que impide esta valorización hasta su realización. ${ }^{26}$

Valencia Restrepo explica: "Los contratos onerosos se dividen en conmutativos o aleatorios, según que las partes, al momento de contratar, conozcan o no con certeza las correspondientes prestaciones y, por tanto, puedan apreciar o no de inmediato la utilidad y el gravamen que de ellas derivan". ${ }^{27}$

De igual parecer es Ospina, quien afirma:

Se entiende que un acto jurídico no es aleatorio cuando los resultados económicos que está llamado a producir se pueden apreciar con más

25 DE LA PUENTE Y LAVALLE, Manuel. Op. cit., p. 94.

26 PLANIOL, Marcel y Georges RIPERT. Compendio de derecho civil. México D.F.: Editorial Pedagogía Americana, 1996, p. 819.

27 VALENCIA RESTREPO, Hernán. Teoría general de la compraventa. Bogotá: Temis, 1983, p. 53. 
o menos precisión desde el momento mismo de su perfeccionamiento. Por el contrario, si en tal momento no puede hacerse dicha estimación, porque la utilidad o el sacrificio que el acto haya de reportar a quienes participan en él depende del azar o aleas, será aleatorio. ${ }^{28}$

Ajuzgar por Rezzónico, la compraventa es un contrato "generalmente conmutativo porque casi siempre las ventajas son ciertas para ambas partes desde el momento mismo en que contratan y la prestación u obligación del comprador y del vendedor son consideradas equivalentes la una de la otra".$^{29}$

Según Lete del Río, el contrato de compraventa es “ordinariamente, conmutativo, porque las prestaciones de los contratantes suelen estar determinadas sin riesgo de pérdida o ganancia. No obstante, mediante pacto expreso, se puede configurar el contrato como aleatorio". ${ }^{30}$

Por su parte, Trincavelli comenta que la compraventa "es habitualmente conmutativa porque en la mayoría de los casos las ventajas están determinadas desde el momento de la celebración del contrato" ${ }^{31}$

Díez-Picazo afirma que “Existe conmutatividad porque, normalmente, a partir de la conclusión del contrato es posible conocer las ganancias obtenidas por cada contratante, que no depende de circunstancias todavía desconocidas, de riesgo o de azar, aunque puedan existir algunas compraventas que son excepcionales aleatorias" ${ }^{32}$

Y Gómez Estrada expresa:

${ }^{28}$ OSPINA FERNÁNDEZ, Guillermo y Eduardo OSPINA ACOSTA. Teoría general del contrato y de los demás negocios jurídicos. Santa Fe de Bogotá: Editorial Temis S.A., 1994, p. 55.

29 REZZÓNICO, Luis María. Op. cit., p. 14.

30 LETE DEL RÍO, José M. Derecho de obligaciones. Madrid: Editorial Tecnos S.A., 1990, p. 22.

31 TRINCAVELLI, Nélida E. La compraventa en Roma. Buenos Aires: Lerner Editores, 1970, p. 38.

32 DÍEZ-PICAZO, Luis y otro. Sistema de derecho civil. 2. ${ }^{a}$ edición. Volumen II. Madrid: Editorial Temis, 1980, p. 317. 
Como de ordinario la utilidad que resulta de la compraventa para ambos contratantes es equivalente, el contrato es por regla general conmutativo; pero como en ocasiones el contrato de compraventa envuelve una perspectiva incierta de ganancia o pérdida o en general un alea, como se compra la suerte en la hipótesis de que trata la parte final del art. 1869 (ampio spei), la compraventa también puede ser contrato aleatorio... ${ }^{33}$

De igual manera opina Borda: "El contrato de compraventa tiene las siguientes características (...) e) es conmutativo porque es de su naturaleza que los valores intercambiados (cosa y precio) sean aproximadamente equivalentes; sólo por excepción suele ser aleatorio, lo que ocurre cuando se compra una cosa que puede o no existir". ${ }^{34}$

Al parecer de Wayar, la compraventa, por lo común, es un contrato conmutativo, pues la existencia y cuantía de las prestaciones que deben cumplir ambas partes son ciertas, es decir, conocidas a priori. Así, tanto el vendedor como el comprador tienen conocimiento cierto, al tiempo de formarse la convención, de la existencia y cantidad (quantum) de las respectivas obligaciones. Por el contrario, cuando una prestación sea incierta, el contrato dejará de ser conmutativo para convertirse en aleatorio. $^{35}$

De Buen sostiene que la compraventa es un contrato conmutativo, no obstante lo cual, en algún caso puede revestir el carácter de aleatorio: es el caso de la compra de una cosa sin la seguridad de que llegue a existir, pagándose, desde luego, el precio. ${ }^{36}$

Etcheverry afirma que hay compraventas que son conmutativas y otras que no lo son. Se da el primer supuesto cuando, al celebrarse el contrato, las prestaciones de las partes son ciertas y determinadas. Si la

33 GÓMEZ ESTRADA, César. Op. cit., p. 5.

34 BORDA, Guillermo. Op. cit., pp. 168-169.

35 WAYAR, Ernesto C. Op. cit., p. 22.

${ }^{36}$ COLIN, Ambroise y Henri CAPITANT. Curso elemental de derecho civil. Tomo IV. Madrid: Instituto Editorial Reus, 1955, p. 13. 
compraventa es de cosa futura o sometida a riesgo, ella es aleatoria y no conmutativa. El citado autor dice que, salvo estos casos, la compraventa siempre supone un equilibrio de prestaciones, desde que el ordenamiento no admite el traspaso de bienes de una persona a otra sin contraprestación alguna. ${ }^{37}$

Belluscio, por su parte, opina que "El contrato de compraventa tiene los siguientes caracteres: (...) d) Conmutativo. Porque al celebrarse el contrato las prestaciones de las partes son ciertas. Sin embargo, si la compraventa es de cosa futura o de cosa sometida a riesgo, la compraventa deja de ser conmutativa y pasa a ser aleatoria". ${ }^{38}$

Dice Lafaille que el contrato de compraventa,

Tanto puede ser conmutativo como aleatorio. En general es el primero por cuanto de antemano cabe conocer cuál es la ventaja que cada uno de los interesados debe obtener en la convención; pero excepcionalmente, se convierte en aleatorio cuando se contrata sobre simple esperanza, esto es sobre una cosa susceptible de llegar o no a existir, tomando el comprador dicho riesgo a su exclusivo cargo....

Y Spota suscribe, acerca de la compraventa, que "Es un contrato conmutativo, pero esto por regla general. Sabemos que el contrato conmutativo es aquel en el cual las prestaciones, al celebrarse esa convención, son ciertas (...). Lo que se opone al contrato conmutativo es el aleatorio, o sea, aquel en que una o todas las prestaciones dependen de un hecho incierto". ${ }^{40}$

37 ETCHEVERRY, Raúl Aníbal. Derecho comercial y económico (Contratos). Parte especial I. Buenos Aires: Editorial Astrea, 1991, pp. 7 y 8.

38 BELLUSCIO, Augusto C. Código Civil y leyes complementarias. Buenos Aires: Editorial Astrea, 1988, p. 369.

39 LAFAILLE, Héctor. Curso de contratos. Tomo II. Buenos Aires: Biblioteca Jurídica Argentina, 1928, pp. 6 y 7.

40 SPOTA, Alberto G. Contratos. Volumen IV. Buenos Aires: Ediciones Depalma, 1980, p. 13. 
Como se aprecia, la doctrina está dividida y, aunque no hay una opinión predominante, nos inclinamos por la segunda posición doctrinaria, considerando que el precio que pactan las partes contratantes es siempre una apreciación subjetiva y, por tanto, aquellas no pueden saber con exactitud cuál es el beneficio o la pérdida que le ocasionará tal transacción de manera objetiva. Entonces, el contrato de compraventa será conmutativo cuando las prestaciones, al celebrarse el contrato, sean ciertas, y será aleatorio cuando la existencia de una o todas las prestaciones dependan de un hecho incierto.

Así por ejemplo, si compramos un automóvil que nos servirá para movilidad, podemos valorar su utilidad en $\$ 100$ diarios, por un tiempo aproximado de dos años. Pero puede ocurrir que hayamos cometido un error al calcular las ganancias que esperábamos obtener, al no considerar que el automóvil adquirido es de baja calidad, con costos de mantenimiento muy altos, que al tercer mes de su adquisición podría suceder un accidente, etcétera, todo lo cual provocará que el resultado de nuestro análisis de costo beneficio no sea el esperado. No existe una transacción con riesgo cero; siempre habrá riesgos y lo que trataremos de hacer es disminuirlos o evitarlos.

Si estimáramos que un contrato es aleatorio cuando no podemos determinar los beneficios o las pérdidas que nos ocasionará, entonces todos los contratos serían aleatorios. Por ello, entendemos que dicho concepto sólo debería aplicarse en el caso de que una de las prestaciones pactadas en el contrato no llegue a existir.

Por otro lado, sabemos que la mayoría de la doctrina establece que la compraventa es un contrato esencialmente conmutativo, es decir, que las prestaciones que se deben las partes son ciertas. Al decir ciertas nos estaríamos refiriendo también al tema del precio cierto, es decir, al precio que tiene como única condición su existencia misma. De manera tal que quedaría descartada la otra posibilidad, referida a que cada una de las partes, al momento de obligarse, puede apreciar de inmediato el beneficio o la pérdida que le ocasionará tal acto. ${ }^{41}$

41 BORDA, Guillermo A. Manual de contratos. Buenos Aires: Editorial Perrot, 1973, p. 160; ETCHEVERRY, Raúl Aníbal. Derecho comercial y económico (Contratos). 
En el contrato de compraventa, las partes, al momento de suscribirlo, no pueden saber con exactitud cuál es el beneficio o la pérdida que les ocasionará tal acto; es decir, no pueden efectuar un análisis objetivo de costo-beneficio; esto, justamente, por el problema de los costos de transacción en que incurrimos al negociar en un mercado de competencia imperfecta, donde uno de los costos que debemos afrontar es, precisamente, conseguir la información necesaria para efectuar nuestras transacciones. Sin embargo, resulta tan costoso obtener esa información, que los economistas comentan que en la mayoría de las ocasiones sería irracional aun intentar conseguirla, debido a que el beneficio que se obtendría resultaría finalmente munúsculo en comparación con los altos costos en los que se habría incurrido.

En cuanto a los supuestos que se plantean para el caso del precio determinable, existirá un precio si este llega a determinarse de acuerdo con ciertos parámetros fijados por las partes contratantes, no importando que el monto al que dicho precio ascienda no sea conocido al momento de suscribirse el contrato.

A este respecto, en el primer punto señalamos que en la economía existen principios fundamentales, como el de costo-beneficio, el cual propone que los sujetos que participan en el mercado buscan obtener el máximo beneficio al menor costo posible, por lo que los economistas opinan que somos "individuos maximizadores". De esta manera, los sujetos que actúan en el mercado buscarán normalmente obtener el mayor beneficio posible en cada una de sus transacciones; por eso, antes de efectuar una transacción, analizarán el beneficio o la pérdida que eventualmente obtendrán como resultado de ella, y solo si piensan que obtendrán una ganancia se decidirán a efectuarla. Sin embargo, ya vimos que dicho análisis está plagado de subjetividades que hacen imposible una decisión plenamente eficiente, pues la mayoría de las veces actuaremos solo por intuición.

Parte especial I. Buenos Aires: Editorial Astrea, 1991, pp. 8 y 9; ARIAS SCHEREIBER PEZET, Max. Exégesis del Código Civil peruano de 1984. Tomo II. Lima: Gaceta Jurídica Editores, 1996, p. 20; TORRES VÁSQUEZ, Aníbal. Acto jurídico. Lima: Editorial San Marcos, 1998, p. 159; BELLUSCIO, Augusto. Op. cit., p. 369; MAZEAUD, Henri, Jean y León. Op. cit., p. 17; MUÑOZ, Luis. Op. cit., p. 181. 
También es necesario recordar el principio de la aversión al riesgo, ${ }^{42}$ que señala que los individuos normalmente son renuentes al riesgo y prefieren las cosas seguras y los resultados menos inciertos. Por ese motivo, los economistas piensan que las actividades que reducen la incertidumbre o el riesgo del consumo de los individuos son las que mejoran el bienestar económico de la sociedad en general. ${ }^{43}$ Pero, como se vio, solo en un mercado de competencia perfecta no existirían costos de transacción; es decir, solo en ese mercado ideal se estaría plenamente informado y, muy probablemente - conforme al principio de costobeneficio-, las partes contratantes, en su condición de individuos maximizadores, buscarían obtener el mayor beneficio al saber con exactitud el resultado económico de sus transacciones.

Sin embargo, en la realidad los mercados son imperfectos y, por tanto, existen deficiencias, como la falta de información, que impiden tomar decisiones plenamente eficientes basadas en apreciaciones objetivas. Justamente, ese es un factor fundamental que no podemos descuidar a la hora de establecer nuestra posición.

Hacer un contrato absolutamente completo, en el que las partes puedan describir todos los riesgos y se imputen a una de ellas, es, en la realidad de los hechos, absolutamente imposible; nunca se podrá hacer un contrato que cubra todas las posibles contingencias. Por eso, se dice que solo hay contratos incompletos (como los contratos que prevén una cantidad necesariamente limitada de supuestos de hecho, de contingencias

42 Según Samuelson, ganador del Premio Nobel en Economía, los individuos generalmente son renuentes al riesgo, pues prefieren una cosa segura antes que unos niveles de consumo inciertos; es decir, prefieren los resultados menos inciertos. Por esta razón, las actividades que disminuyen la incertidumbre y el riesgo del consumo son las que mejoran el bienestar económico. SAMUELSON, Paul A. Op. cit., pp. 190 y 191.

43 Sin embargo, en el caso del precio determinable, las partes contratantes prefieren los resultados inciertos y se sienten atraídos hacia el riesgo. En este supuesto, ninguna de las partes sabe cuál es el beneficio o la pérdida que le ocasionará tal acto; en otras palabras, juegan una lotería, y las probabilidades ni siquiera están determinadas para suponer que tienen un incentivo económicamente razonable. 
en que debe transcurrir el contrato). Es por ello que algunos estudiosos del análisis económico piensan que, en el caso del precio determinable, el motivo básico de la indeterminación se debe a los costos de transacción: las partes dejan sin regular una parte del contrato porque los costos de prever y negociar una determinada contingencia son mayores que los posibles beneficios que se derivan de regular esa contingencia. Entonces, para juzgar si un coste cualquiera es elevado o reducido debe compararse con las consecuencias que resultarían de prescindir de él. En ese orden de ideas, podría darse el caso de que el coste de la indeterminación sea menor al de transacción, lo que podría deberse a que el coste de la indeterminación sea muy bajo (superdeterminación ${ }^{44}$ ) o a que el coste de transacción sea muy alto (irrelevancia del disenso ${ }^{45}$ ).

${ }^{44}$ La "superdeterminación" se produce cuando el contexto concreto en que tiene lugar el acuerdo proporciona a los contratantes un precio que estos pueden conocer fácilmente y sin costo adicional. El contexto en que se produciría la indeterminación sería contractual (los usos de un conjunto de personas o la repetición de contratos entre las mismas partes) o institucional (que se identifica con lo que la doctrina denomina evidentes, indiscutibles, inconmovibles o notorios, como los fijados administrativamente, los monopolios, las tarifas de aprobación oficial, o los que se negocian en un mercado organizado con cotización oficial). La función que pretenden cumplir las normas que regulan ese entramado de precios y garantizar su evidencia estará dada, justamente, para facilitar la transparencia del mercado y reducir los costes de transacción. FAJARDO FERNÁNDEZ, Javier. La compraventa con precio determinable. Madrid: Editorial Edijus, 2001, pp. 235-238.

45 Entiéndase bien que el precio no es nunca irrelevante, sino, en algunos casos, su determinación (la fijación exacta de la cuantía). La irrelevancia del disenso se produce cuando ambos contratantes saben que pretenden precios distintos y que el coste de llegar a un acuerdo sobre el precio promete ser elevado, pero, a pesar de todo, prefieren contratar a que el disenso impida el contrato. Esto se debería a que en ocasiones las diferencias entre el comprador y el vendedor carecen de relevancia frente a la necesidad de contratar. Como el coste de fijar el precio debe ponerse en relación con el coste de oportunidad de no llegar a contratar, el disenso puede ser irrelevante: cada parte prefiere que haya contrato y pretende que el precio se acerque al suyo, pero, en caso de no lograrlo, está dispuesta a aceptar el de la otra parte como mal menor, porque el riesgo 
Evidentemente, estas son muy buenas explicaciones del por qué razonablemente elegiríamos un contrato de compraventa con precio determinable. Sin embargo, como se ha visto, las motivaciones que están detrás de dicha elección son infinitas, como las explicaciones sobre el tema. ${ }^{46}$

\section{La naturaleza jurídica del tercero designado por las partes con- tratantes}

El artículo 1544 del Código Civil dispone: "Es válida la compraventa cuando se confía la determinación del precio a un tercero designado en el contrato o a designarse posteriormente, siendo de aplicación las reglas establecidas en los artículos 1407 y 1408".

de deber o recibir el precio de la otra parte es menor al coste de no contratar ahora. Un ejemplo clásico es el de una fábrica paralizada porque se ha estropeado una cadena de montaje. Lo más seguro es que el fabricante encargue la pieza de repuesto sin preguntar siquiera por su precio, que en cualquier caso será irrelevante frente a los costes de tener la fábrica parada. Una compraventa así tiene un precio determinable. Igual sucede en el caso de un ama de casa al hacer las compras semanales en el hipermercado, donde será normal que compruebe y compare los precios de los productos más relevantes por su cuantía y volumen, pero sin mirar el precio de la sal y la mostaza, aunque le conste que podría encontrar esos productos a mejor precio en otro sitio; sin embargo, en el conjunto del contrato que va a realizar con el almacén, su precio le da igual. Íd., op. cit.

${ }_{46}$ Al respecto, Fajardo Fernández comenta: “En conclusión, el miedo a la indeterminación del precio no está justificado. Suele provenir de la reflexión abstracta, más que de la observación de la realidad (...). Con frecuencia, la oposición a admitir lo indeterminado nace de olvidar que toda indeterminación voluntaria responde a alguna finalidad; toda indeterminación delimitada es una cierta determinación relativa. La mayor parte de las veces, la indeterminación surge porque las partes dejan sin regular, voluntariamente, algún punto del contrato. No hay que temerla, sino delimitarla, entenderla, completarla. Entonces dejará de ser un 'agujero negro' del que el derecho debe huir, para convertirse en un 'espacio vacío' que es completado por los 'espacios llenos' que lo delimitan”. FAJARDO FERNÁNDEZ, Javier. Op. cit., p. 56. 


\subsection{Carácter de la función del tercero}

Se discute en doctrina respecto al carácter que desempeña el tercero, planteándose las figuras del perito, el mandatario, el árbitro y el arbitrador.

Así por ejemplo, Pothier, ${ }^{47}$ Aubry y Rau $^{48}{ }^{48}$ Laurent $^{49}$ Gasca $^{50}$ y Josserand ${ }^{51}$ consideran que el tercero que fijará el precio es un perito. A este respecto, De la Puente y Lavalle, ${ }^{52}$ acertadamente, aclara que "es preciso descartar la figura del perito, dado que su dictamen no tiene carácter vinculante para las partes o para el juez, mientras que la fijación del precio por tercero será obligatorio para las partes".

Otro sector de la doctrina, al que pertenecen, entre otros, Planiol y Ripert, ${ }^{53}$ Mazeaud ${ }^{54}$ Borda $^{55}$ Salvat,${ }^{56}$ Wayar ${ }^{57}$ y Castillo Freyre, ${ }^{58}$ considera que el tercero juega el rol de mandatario de las partes contratantes $y$, por ello, el vendedor y el comprador están obligados a respetar y acatar sus decisiones al haberlo designado de común acuerdo.

Bianca refuta esta hipótesis, afirmando que si bien es cierto que el tercero se sustituye a las partes en la determinación de la relación contractual, no podría decirse que por ello asume el ropaje de un representante. La figura del representante, aclara, destaca por su poder representativo externo, esto es, por el poder de cumplir un acto que compro-

47 POTHIER, Robert Joseph. Tratado de contratos. Tomo I. Buenos Aires: Editorial Atalaya, 1948, pp. 18 y 19.

${ }_{48}$ Citado por CASTILLO FREYRE, Mario. Op. cit., p.189.

49 Íd., op. cit.

50 GASCA, C.L. Op. cit., p. 557.

51 JOSSERAND, Louis. Derecho civil. Tomo II, volumen II. Buenos Aires: Editorial Bosch, 1952, p. 13.

52 DE LA PUENTE Y LAVALLE. Op. cit., p. 103.

53 Op. cit., p. 191.

54 MAZEADUD, Henri, Jean y León. Op. cit., p. 143.

55 BORDA, Guillermo A. Op. cit., p. 198.

56 SALVAT, Raymundo. Op. cit., p. 305.

${ }^{57}$ WAYAR, Ernesto. Op. cit., p. 278.

${ }_{58}$ CASTILLO FREYRE, Mario. Op. cit., p. 200. 
mete al representado frente a terceros. La persona designada, en cambio, no se avala de un poder de tal naturaleza, pues su determinación queda en el ámbito de la relación ya constituida entre las partes que han recurrido a su arbitrio: el tercero no ejercita ningún poder en nombre ajeno, sino que desarrolla su actividad en nombre propio, con efecto sobre la relación contractual según lo establecido por las partes. ${ }^{59}$

$\mathrm{Al}$ respecto, Planiol y Ripert, al analizar las sentencias judiciales que consideran esta función como un mandato, afirman que "esto provoca algunas dificultades, pues el papel del mandatario es una simple facultad de representación, y se trata de tener una voluntad independiente de las partes". ${ }^{60}$

Esta posición parecería concordar con la opinión de Díez-Picazo, quien considera que, como en el caso propuesto, en el que uno de los elementos del negocio no haya sido determinado, se podría originar un conflicto de intereses que pondría en riesgo o peligro la independencia o rectitud del representante; esto debido a que en la determinación del precio existen intereses contrapuestos de parte del comprador y el vendedor, quienes buscarán obtener el máximo beneficio posible a costa de la otra parte. ${ }^{61}$

Por otro lado, autores como Josserand $\mathrm{d}^{62}$ y Laurent ${ }^{63}$ piensan que las partes pueden dejar la determinación del precio al arbitraje de un tercero. A este respecto, De la Puente y Lavalle comenta que el artículo 1407 del Código Civil - al cual hace referencia el artículo 1544 del mismo código - habla de confiar la determinación de uno de los elementos del contrato al arbitrio de tercero, por lo cual se ha pensado que esta función será de un arbitrio. Esta doctrina no podría ser aceptada porque el arbitraje supone siempre un litigio entre las partes, mientras que en el

59 BIANCA C., Massimo. La vendita e la permuta. Torino: Unione Tipográfica/ Editrice Torinese, 1972, p. 329.

60 PLANIOL, Marcel y Georges RIPERT. Op. cit., p. 918.

${ }^{61}$ DÍEZ-PICAZO, Luis. La representación en el derecho privado. Madrid: Editorial Civitas S.A., 1979, pp. 199-214.

62 JOSSERAND, Louis. Op. cit., p. 13.

63 Citado por CASTILLO FREYRE, Mario. Op. cit., p. 189. 
caso del artículo 1544 del Código Civil no existe litigio, sino solo la conclusión del contrato de compraventa. Cita a continuación a Díez-Picazo, quien manifiesta que "se trata de un problema terminológico que desde antiguo ha sido resuelto distinguiendo entre el árbitro y el arbitrador, correspondiendo al primero llevar a cabo un arbitraje y al segundo una operación de arbitrio, es decir ejercitando su facultad de decisión". En tales condiciones, dice el autor, lo más acertado es darle al tercero que ha de fijar el precio una calidad autónoma: la de arbitrador. ${ }^{64}$

Esa es también la posición de Giuseppe Chiovenda, quien hace la distinción entre las nociones de árbitro y arbitrador, de la siguiente manera:

Desde hace tiempo se discute doctrinariamente la diferencia entre árbitro y arbitrador. El árbitro conoce de una relación litigiosa, como de ella conocería el juez. El arbitrador está llamado a determinar una relación pacífica en sí misma, un elemento no definido por las partes (por ejemplo, el precio de una venta, la participación de un socio en una sociedad) (...). El arbitrador no declara derechos existentes, sino que completa relaciones jurídicas, lo cual no tiene importancia sino para el derecho civil. ${ }^{65}$

Nosotros estamos de acuerdo con esta última posición, propugnada también por Lafaille, ${ }^{66}$ Bianca, ${ }^{67}$ Rezzónico ${ }^{68}$ Gómez Estrada, ${ }^{69}$ Messineo, ${ }^{70}$ Muñoz, ${ }^{71}$ entre otros, quienes aceptan esta distinción, utilizando el nombre de arbitrador para designar a la persona a cuyo arbitrio se someten las partes.

DE LA PUENTE Y LAVALLE, Manuel. Op. cit., p. 103.

Citado por GÓMEZ ESTRADA, César. Op. cit.

${ }_{66}$ LAFAILLE, Héctor. Op. cit., p. 65.

67 BIANCA C., Massimo. Op. cit., p. 462.

68 REZZÓNICO, Luis María. Op. cit., p. 157.

${ }_{69}$ GÓMEZ ESTRADA, César. Op. cit.

70 Íd., op. cit.

${ }^{71}$ MUÑOZ, Luis. Op. cit., p. 310. 


\subsection{Número de arbitradores}

Si bien el artículo 1544 del Código Civil habla de confiar la determinación del precio a un tercero (en singular), según la doctrina mayoritaria no hay inconveniente en que haya más de un arbitrador.

Si los arbitradores son varios, su actuación se efectuará de acuerdo con lo que dispone el acto de nombramiento. Si nada se dijera sobre el particular, surge el delicado problema de establecer si el acuerdo entre los arbitradores debe ser adoptado por mayoría o por unanimidad.

Wayar cita el artículo 2006 del Esbozo de Freitas, según el cual, si los terceros a cuyo arbitraje fue dejada la determinación del precio estuviesen en discordia, decidirá la mayoría de votos. Badenes sostiene que aun cuando el criterio de la unanimidad parezca más conforme a la naturaleza del acto, el sentido de la mayoría tiene la ventaja práctica de facilitar la obtención del acuerdo, disminuyendo en gran medida los obstáculos que la unanimidad puede presentar. ${ }^{72}$

Manresa, por su parte, considera que cuando las partes no han manifestado expresamente que en caso de disentimiento se esté a lo que resuelva la mayoría, es presumible que han querido seguir la opinión unánime de todos los arbitradores, pues en realidad la opinión de la mayoría no es la opinión de todos, y si los contratantes se han sometido al criterio de todos, este y no otro, por autorizado que parezca, es el que hay que seguir. ${ }^{73}$

Criterio parecido tiene López de Zavalía al decir que si bien hay quienes opinan que la decisión debe ser adoptada por la mayoría, él entiende que para ello haría falta, en ausencia de la voluntad explicitada, una norma supletoria.

Por su parte, De la Puente y Lavalle ${ }^{74}$ opina que si se han designado varios arbitradores para que actúen conjuntamente, debe considerarse que es porque se desea que todos ellos participen en la determinación

72 WAYAR, Ernesto. Op. cit., p. 286.

73 Citado por DE LA PUENTE Y LAVALLE, Manuel. Op. cit., p. 104.

74 DE LA PUENTE Y LAVALLE, Manuel. Op. cit., p.105. 
del precio, lo cual no ocurriría si la decisión es tomada por la mayoría, desde que la minoría tendría un parecer diferente. ${ }^{75}$

Ambas posiciones doctrinarias tienen un sustento razonable, por lo que nos inclinamos a pensar que, en caso de que se hayan designado dos o más arbitradores, las partes contratantes deberían estipular la manera de llegar a un acuerdo. Si no se hubiera establecido dicho procedimiento, debería primar el criterio de la unanimidad, considerando que la voluntad de las partes es que todos los arbitradores determinen el precio, siendo la opinión de cada cual fundamental a la hora de establecer la decisión final.

\subsection{Carácter de la designación}

La doctrina mayoritaria sostiene que el precio puede ser determinable siempre y cuando se hayan fijado los criterios que permitan establecerlo con certeza, sin influencia posterior de las partes.

A este respecto, Torres Méndez sostiene que el precio que debe determinarse por un tercero es un caso de precio determinable y no de precio indeterminado. Agrega que cuando las partes han acordado que el precio va a determinarlo un tercero, ello significa que si bien aún no está determinado, las partes han fijado al menos el modo de hacerlo; por esa razón, el precio es determinable siempre y cuando se haya cumplido con el requisito de la certidumbre. Cita a C. Massimo Bianca, quien expresa que "el deferir a la decisión de un tercero no importa un negocio incompleto. En cuanto las partes hayan fijado el procedimiento de determinación del precio, ellas han hecho a este último determinable, expresando así aquella indicación mínima del objeto que es suficiente para el surgimiento del vínculo contractual. ${ }^{76}$

Entonces, puede concluirse que en nuestro ordenamiento se ha previsto la actuación del tercero como uno de los mecanismos previstos contractualmente para la determinación del precio, es decir, para convertir en determinado lo que sólo era determinable.

75 LÓPEZ DE ZAVALÍA, Fernando. Teoría de los contratos. Tomo II. Parte especial. Buenos Aires: Víctor P. de Zavalía Editor, 1976, p. 84.

76 TORRES MÉNDEZ, Miguel. Op. cit., p. 210. 


\subsection{Naturaleza jurídica de la referencia al arbitrio del tercero}

Acerca de este tema existen muchas teorías que, si bien no son tema de nuestro trabajo, expondremos brevemente para luego dar nuestra opinión.

Demante entiende que se podría tratar de un contrato sujeto a condición suspensiva:

Cuando se ha convenido en fijar el precio en base corriente del mercado, se podría estar tentado de decir igualmente que la venta es pura y simple; sin embargo, como los acontecimientos políticos, o accidentales, inundaciones, incendios del día indicado, pueden consistir en obstáculos a la uniformidad del mercado del día indicado, será necesario reconocer que la venta depende de una eventualidad, que ella es con-

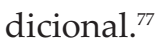

A esta tesis se adhieren Baudry, ${ }^{78}$ Aubry y Rau, ${ }^{79}$ Machado,${ }^{80}$ Lafaille, ${ }^{81}$ Acuña Anzorena, ${ }^{82}$ López de Zavalía, ${ }^{83}$ Rezzónico, ${ }^{84}$ Castillo Freyre, ${ }^{85}$ entre otros.

No estamos de acuerdo con esta posición, porque implica considerar que el precio esta inmerso en una condición, lo cual sería negar que puede ser determinable y que constituye un elemento esencial del contrato de compraventa. Así opinan Paolo Greco y Gastone Cottino: “En jurisprudencia se ha hablado a este respecto de la venta bajo condición suspensiva: calificación que nos deja perplejos, ya que la condición no puede abordar un elemento esencial del contrato". ${ }^{86}$ 
Además, hay que considerar la importancia y trascendencia jurídica de precisar si la condición suspensiva suspende la existencia del contrato o suspende su eficacia. Pothier, ${ }^{87}$ Planiol $^{88}$ y Rezzónico ${ }^{89}$ consideran que el contrato que se ha suspendido no existe y que tiene la esperanza de nacer algún día. Por su parte, Enneccerus,,$^{90}$ Kelsen $^{91}$ y Gutiérrez González ${ }^{92}$ consideran que, por el contrario, el contrato sujeto a condición suspensiva ya nació y existe como cualquier otro, con la variante de que solo sus efectos están en suspenso. Como vemos, en nuestro caso, según la primera posición, el contrato de compraventa no existiría en tanto se determine el precio. Según la segunda posición, en cambio, el precio, por ser un elemento esencial del contrato de compraventa, no podría estar inmerso en una condición suspensiva, pues ello implicaría aceptar que, al no estar reunidos todos los elementos del contrato, este no existiría en tanto se produzca la condición, que es lo que precisamente intentan negar. ${ }^{93}$ Además, según Betti, la explicación del precio deter-

Citado por GUTIÉRREZ Y GONZÁLEZ, Ernesto. Derecho de obligaciones. 10. a edición. México D.F.: Editorial Porrúa S.A., 1995, p. 877.

88 Íd., op. cit.

89 REZZÓNICO, Luis María. Op. cit., p. 171

90 Íd., op. cit.

91 Íd., op. cit.

92 Íd., op. cit.

93 A este respecto, León Barandiarán planteaba su duda de si se trata de un contrato sujeto a una condición suspensiva o si simplemente no hay contrato alguno: “El artículo 1387 [del Código Civil de 1936] dice que si el tercero no señala el precio, caduca la venta. Esto vendría a significar que el contrato se ha producido, que ya ha habido compraventa, sólo que ella quedó sometida a una condición a realizarse; que ya las partes habían decidido la compraventa, faltando sólo la concreción del quantum del precio. Pero, de otro lado, es de juzgar que propiamente no ha habido contrato, que éste sólo surge cuando el precio resulta fijado; de modo que antes sólo existió un ante-acto; de suerte que las partes no pueden retractarse; pero no estimándose que haya habido contrato, porque éste no llegó a perfeccionarse" (LEÓN BARANDIARÁN, José. Op. cit., pp. 18). Asimismo, Larroument opina que "una condición nunca puede recaer sobre un elemento esencial del contrato; sólo puede referirse a elementos accesorios, y no puede ser sino modalidad del contrato, y nunca es una condición de validez del contrato" (LARROUMENT, Christian. Teoría general del contrato. Volumen I. Bogota: 
minable como condicional estaría desfasada, pues, mientras el negocio condicional está completo y somete la producción de sus efectos a una circunstancia accidental, el que tiene precio determinable está incompleto y somete a un hecho externo el elemento que le falta, pero no la eficacia negocial. ${ }^{94}$ A esta posición se adhieren Hernández Gil,${ }^{95}$ Castán, ${ }^{96}$ García Cantero, ${ }^{97}$ Badenes, ${ }^{98}$ Bianca, ${ }^{99}$ Criscuolo, ${ }^{100}$ Gernhuber, ${ }^{101}$ Staudinger, ${ }^{102}$ entre otros. ${ }^{103}$

Por otra parte, Gómez Estrada opina que,

Por último, algunos consideran (Planiol y Ripert) que cuando en el caso del art. 1865 se deja al arbitrio de un tercero la fijación del precio de la compraventa, el contrato no existirá sino hasta tanto ese tercero fije el precio. En los eventos citados, pues, se dan situaciones en que está afectado el contrato en su integridad, como un todo, pero en ellos, en realidad, se trata de casos de conditio juris, y por tanto de negocios incompletos más bien que condicionados. ${ }^{104}$

Editorial Temis S.A., 1993). Igualmente, Degni opina que "La condición debe referirse a un acontecimiento extraño a los elementos esenciales del negocio jurídico, que deben suponerse existentes" (DEGNI, Francisco. La compra-venta. Madrid: Editorial Revista de Derecho Privado, 1957, p. 116).

${ }^{44}$ Citado por FAJARDO FERNÁNDEZ, Javier. Op. cit., p. 216.

95 Íd., op. cit.

96 Íd., op. cit..

${ }_{97}$ Íd., op. cit.

98 Íd., op. cit.

99 Íd., op. cit.

100 Íd., op. cit.

101 Íd., op. cit.

102 Íd., op. cit.

${ }^{103}$ A este respecto, Fajardo Fernández alega que "al contrario de la obligación de pagar el precio, cuya exigibilidad y cumplimiento se encuentran obstaculizados notablemente cuando no se puede conocer la cuantía debida, en principio nada impide que el vendedor cumpla sus obligaciones. Esto muestra hasta qué punto es inadecuada al contrato con precio determinable la aplicación del modelo condicional suspensivo, que llevaría a suspender la exigibilidad de esta obligación". Op. cit., p. 519.

104 GÓMEZ ESTRADA, César. Op. cit., p. 28. 
Al respecto, Degni apunta que "la conditio iuris, impropiamente dicha tal, es más el presupuesto para la eficacia de algunos negocios jurídicos que se suponen ya perfectos en todos sus elementos sustanciales" ${ }^{105}$ Igualmente, Espín considera que "la crítica a la venta condicionada, pretende obviarse configurando una conditio iuris, pero se observa que subsiste la dificultad de elevar a requisito de eficacia un elemento esencial del contrato" ${ }^{106}$ Según Puig Peña, una de las notas fundamentales de la condición es "que el acontecimiento que integra la condición no forme parte de los elementos típicos del negocio; por lo que no son tales las llamadas condictiones iuris, o sea, aquellos supuestos o circunstancias que son necesarios para que el negocio produzca sus efectos" ${ }^{107}$

Por su parte, De la Puente y Lavalle comenta:

Con la finalidad de obviar la dificultad que - en el Derecho italiano, francés y español- presenta la retroactividad de la condición, algunos autores, entre quienes cabe citar a De Martini y Cariota-Ferrara, han intentado utilizar el expediente de la conditio iuris que, según Messineo, no es verdadera y propia condición y, por consiguiente, tampoco elemento accidental del negocio, sino que constituye un requisito objetivo al que está subordinada la eficacia del negocio. Sin dicho requisito, agrega, el negocio no puede ser eficaz, aun cuando las partes se hayan abstenido de hacer depender de él la suerte del negocio mismo, desde que la conditio iuris es sobreentendida o tácita. El reflejo práctico del desconocimiento a la conditio iuris del carácter de condición en sentido técnico, está en la no aplicabilidad de las normas reguladoras de la condición propia y, sobre todo, del principio de la retroactividad: de ahí que el negocio viene a ser eficaz ex nunc o sea desde el momento en que sobreviene la conditio iuris. ${ }^{108}$

DEGNI, Francisco. Op. cit.

ESPÍN, Diego. Manual de derecho civil español. Volumen VIII. Madrid: Editorial Revista de Derecho Privado, 1983, p. 559.

PUIG PEÑA, Federico. Tratado de derecho civil español. Tomo IV, volumen II. Madrid: Editorial Revista de Derecho Privado, 1974, p. 29.

DE LA PUENTE Y LAVALLE, Manuel. Op. cit., pp. 54 y 55. 
Luego, como se observa, la compraventa con precio determinable no sería un contrato condicionado; dicho acuerdo, entonces, no sería ni una condición suspensiva ni una conditio iuris.

Así opina Badenes Gasset, quien, comentando el Código Civil español, nos dice: "Observando el artículo 1447 se ha llegado a la conclusión de que en él existe, además del contrato de compraventa, un segundo acuerdo de las partes sobre la manera de llevar a cabo la determinación del precio. Este segundo convenio tiene, respecto del primero, una cierta sustantividad que permite configurarlo como contrato". ${ }^{109}$

Sobre el tema, De la Puente y Lavalle piensa que

El acuerdo entre las partes contractuales sobre sometimiento a la determinación del arbitrador tiene naturaleza jurídica de un pacto, en el sentido de estipulación secundaria que se agrega al acuerdo básico constitutivo del contrato, sin desconocerse con ello que el pacto es en sí un contrato, aunque sea accesorio desde que no puede existir sino vinculado al contrato principal. ${ }^{110}$

Torres Méndez se adhiere a esta opinión, afirmando que

Esta es la verdadera naturaleza jurídica del acuerdo bajo estudio porque, como se ha explicado, el precio a determinarse por un tercero es un precio determinable. De tal manera que el acuerdo por el cual se ha convenido en una compraventa este precio determinable viene a ser, pues, simplemente una parte de este contrato, pero no una parte especial y condicional, sino una parte propia y esencial, además del mismo. ${ }^{111}$

\footnotetext{
109 BADENES GASSET, Ramón. Op. cit., p. 211.

110 DE LA PUENTE Y LAVALLE, Manuel. Op. cit., p. 106.

111 TORRES MÉNDEZ, Miguel. Op. cit., p. 214.
} 
Estamos de acuerdo con esta última posición, pues pensamos que dicho acuerdo es un pacto de carácter accesorio, que no puede existir sino vinculado al contrato principal de compraventa.

\subsection{Momento de efectuar la designación}

El artículo 1544 del Código Civil establece que es válida la compraventa cuando se confía la determinación del precio a un tercero designado en el contrato o a designarse posteriormente, por lo que sería tan válido el contrato en el que se designa al arbitrador, como aquel en que este fuera designado posteriormente.

En efecto, según De la Puente y Lavalle, existiría un error de concepto en el artículo 1544, pues si el pacto de designación de tercero no figurara al celebrarse el contrato, no existiría precio determinado o determinable, lo que acarrearía la nulidad del contrato de compraventa. La designación posterior del arbitrador daría lugar a que solo en el momento de efectuar dicha designación el contrato de compraventa adquiriría validez. Sin embargo, más adelante agrega que si las partes contratantes han estipulado que el precio sea fijado por un tercero, pero no han designado quién será este, entonces se habrá dado inicio al mecanismo de designación, por lo que el contrato será valido, pero no eficaz hasta que efectivamente se efectúe tal designación. ${ }^{113}$

112 Felipe Sánchez Román manifiesta que "el pacto es, en cuanto a su fuerza o eficacia, lo mismo que el contrato, y su diferencia tan sólo consiste en que el primero es una parte del segundo, llamándose así las condiciones o particulares que el contrato contiene o se le adjuntan" (citado por ARIAS SCHEREIBER PEZET, Max. Op. cit., p. 76). Por su parte, De La Puente y Lavalle expone que “El pacto tiene significado muy parecido al de 'estipulación', que se entiende como un acuerdo accesorio, convenido dentro del marco de un contrato típico, que simplemente tiene por finalidad cubrir un punto específico. Separado del contrato, el pacto es, en sí mismo, un contrato" (DE LA PUENTE Y LAVALLE, Manuel. Estudios sobre el contrato privado. Volumen I. Lima: Cultural Cuzco S.A. Editores, 1983, p. 93).

${ }_{113}$ DE LA PUENTE Y LAVALLE, Manuel. El contrato de compraventa, pp. 106-107. 
Sobre el particular, Wayar piensa que lo frecuente será que el tercero sea designado por las partes al momento de la celebración del contrato, hipótesis esta que no ofrecería ninguna dificultad, pues habría simplemente que atenerse a los términos del contrato. Cuando las partes postergan la designación del tercero para un momento posterior a la celebración del contrato, surgen algunos inconvenientes, por lo que el contrato debería considerarse existente desde el momento en que aquellas designen al tercero, para que así se llenen los requisitos del contrato. Antes de dicho acto faltaría un elemento esencial para que aquella convención sea considerada una compraventa. ${ }^{114}$

Por nuestra parte, concordamos con la posición de Laurent, ${ }^{115}$ Lete, ${ }^{116}$ Trincavelli, ${ }^{117}$ Peirano ${ }^{118}$ y Castillo Freyre ${ }^{119}$, entre otros, pues consideramos que en este caso no debería existir contrato de compraventa, debido a que a cualquiera de las partes le bastaría con no contribuir al cumplimiento del mutuo deber de designar al tercero, para que, con base en su exclusiva voluntad, el contrato devenga inejecutable. Sería muy difícil para la parte perjudicada probar, en la práctica, que la otra parte ha actuado culposa o dolosamente, siendo más fácil considerar que se trató de un simple desacuerdo donde no hubo dolo de por medio.

\subsection{Arbitrio de equidad y mero arbitrio}

Conforme al artículo 1544 del Código Civil, son de aplicación los artículos 1407 y 1408, que disponen:

Artículo 1407.- Si la determinación de la obligación que es objeto del contrato es diferida a un tercero y no resulta que las partes quisieron remitirse a su mero arbitrio, el tercero debe proceder haciendo una apreciación de carácter equitativo.

114 WAYAR, Ernesto. Op. cit., p. 2.

115 Citado por CASTILLO FREYRE, Mario. Op. cit., pp. 214 y 215.

116 LETE DEL RÍO, José M. Op. cit., p. 22.

117 TRINCAVELLI, Nélida E. Op. cit., p. 53.

118 PEIRANO FACIO, Jorge y Gustavo ORDOQUI CASTILLO. Op. cit., p. 274.

119 CASTILLO FREYRE, Mario. Op. cit. 
Artículo 1408.- La determinación librada al mero arbitrio de un tercero no puede impugnarse si no se prueba su mala fe.

Si falta la determinación y las partes no se ponen de acuerdo para sustituir al tercero, el contrato es nulo.

La distinción entre el arbitrio de equidad (arbitrium boni vini) y el mero arbitrio simple (arbitrium merum) viene desde el derecho romano.

De la Puente y Lavalle opina que el arbitrio de equidad es aquel en que "el arbitrador debe proceder según un criterio de atemperación de los intereses de los contratantes, o sea, dando cumplimiento a las normas de equidad". El mero arbitrio, en cambio, permite al arbitrador proceder a la determinación según su libre elección. Sin embargo, señala el mismo autor, esto no debería entenderse en un sentido liberal, ya que el artículo 1408 del Código Civil lleva implícita la idea de que el arbitrador no debe proceder de mala fe, de tal manera que la libertad de determinación no sería absoluta, desvinculada de toda motivación, sino que estaría limitada por su necesaria adecuación a la buena fe. ${ }^{120}$

Por su parte, Barassi considera que el arbitrio de equidad es también subjetivo en cuanto que es obra de una valoración individual. Afirma que lo característico del arbitrio de equidad es la valoración objetiva de las circunstancias como lo haría cualquier dirigente y ponderado observador. Equidad, en materia de arbitrio, quiere decir tener en cuenta las circunstancias concretas como lo haría un prudente valorador. ${ }^{121}$

Según Rubino, en el caso del arbitrium merum se da una autorización para actuar con criterios puramente personales, sin tener en cuenta el valor y la opinión media con la cual, en las mismas circunstancias, habría procedido un hombre medio y equilibrado. ${ }^{122}$ Del mismo parecer es Pacchioni, cuando considera que el arbitrium merum no es una decisión arbitraria ni caprichosa, sino un juicio perfectamente serio en el que

DE LA PUENTE Y LAVALLE, Manuel. El contrato de compraventa, p. 108.

Citado por DÍEZ-PICAZO Y PONCE DE LEÓN, Luis. El arbitrio del tercero en los negocios jurídicos. Barcelona: Bosch, 1957, p. 138.

Íd., op. cit. 
lo único que ocurre es que las partes renuncian al control de la posible impugnación, puesto que la fundan en la confianza que merece el tercero. ${ }^{123}$

Acerca de ello, Díez-Picazo comenta:

En definitiva, decir que el arbitrador, a quien se encomienda el señalamiento de un precio, ha de proceder equitativamente, es lo mismo que afirmar que ha de señalar un precio justo. El precio marcado por el arbitrador ha de ser un "iustum pretium" (...). Un precio es justo cuando corresponde al autentico valor de la cosa. Ello lleva a pensar que la justicia del arbitrio (...) es un concepto próximo a la exactitud o, mejor, adecuación a un patrón, a un valor. El problema, entonces, consiste en averiguar si este valor, al que ha de adecuarse la decisión del arbitrador, es un valor subjetivo o, por el contrario, puede medirse objetivamente. La respuesta, "prima facie" dada, se inclina hacia el subjetivismo (...). La diferencia entre arbitrio de equidad y arbitrio simple residiría, entonces, en la característica de la motivación de la decisión del arbitrador. El arbitrador procede con equidad cuando aplica un criterio usual o típico, el criterio normal para la comunidad en la que vive; procede de buena fe cuando da su auténtico parecer, sea acorde o discorde con el general. El arbitrio de equidad es juicio conforme a una idea objetiva de justicia; el arbitrio de buena fe, lo es acorde a la idea subjetiva de quien juzga. ${ }^{124}$

Como se observa, la distinción doctrinaria entre el arbitrio de equidad y el mero arbitrio radica en el carácter de la motivación de la decisión del arbitrador. Por ello, pensamos que para el caso del precio determinable no debería considerarse el arbitrio simple en cuanto sugiere criterios vagos como que la decisión del tercero sea manifiestamente contraria a la equidad, con una desproporción evidente, contraria a los elementos de hecho o a las circunstancias del caso. Se pretende utilizar referentes objetivos para cuestionar la valoración hecha por el tercero,

${ }^{123}$ Íd., op. cit.
${ }^{124}$ Op. cit., pp. 134-141. 
cuando lo único que se le debería exigir es actuar de buena fe, es decir, de acuerdo con su autentico parecer, pues, como se ha visto, la determinación del precio es un proceso absolutamente subjetivo. En ese sentido, sí estaríamos de acuerdo con la aplicación del mero arbitrio como la manera apta para determinar el precio del contrato de compraventa.

\subsection{Presunción de arbitrio de equidad}

Del texto del artículo 1407 del Código Civil se deduce que si no resulta que las partes quisieron remitirse al mero arbitrio del tercero, el arbitrio de este debe ser de equidad, ya que le impone el deber de proceder haciendo una apreciación de carácter equitativo.

La doctrina mayoritaria está de acuerdo con esta solución. Así por ejemplo, Díez-Picazo dice:

La presunción del arbitrio de equidad tiene un fundamento muy claro si el arbitrio se considera como arbitrio libre. En definitiva, la razón sería que la preferencia por un parecer razonable es, usualmente, normalmente mayor a la que pueda tenerse por una opinión que carece de aquella cualidad. Lo normal es que las partes busquen un parecer razonable antes que pura y real voluntad, rayada en la arbitrariedad. Y el ordenamiento jurídico obra con prudencia al presumir la normalidad de la conducta de los sujetos de derecho. ${ }^{125}$

Por nuestra parte, pensamos que la presunción del arbitrio de equidad en el caso del precio determinado por un tercero no tiene un asidero práctico, en la medida en que se pretende utilizar un referente objetivo para cuestionar la valoración hecha por el tercero, cuando lo único que debería exigírsele es actuar de buena fe, es decir, de acuerdo con su autentico parecer, pues, como se ha visto, la determinación del precio es un proceso absolutamente subjetivo y, por tanto, no existiría un criterio objetivo ni económico que sirva para calificar como justa o equitativa la decisión del arbitrador, independientemente de su real voluntad.

${ }^{125}$ Op. cit., pp. 142 y 143. 


\subsection{Impugnación del arbitrio de equidad}

De acuerdo con De la Puente y Lavalle:

Si el arbitrador debe hacer una apreciación equitativa y si la equidad, en este caso, debe juzgarse con carácter objetivo, o sea con un criterio aplicable a la normalidad de la comunidad en que viven las partes, es evidente que esta apreciación puede ser realizada por toda persona que tenga un buen criterio, esto es, que sepa manejar la equidad. En estas circunstancias, si la decisión del arbitrador es impugnada, el remedio más eficaz es que el arbitrador sea sustituido por otras personas que puedan manejar la equidad, entre las cuales sobresale, evidentemente, el juez, debidamente asesorado, desde luego, por los peritos que fuera menester. ${ }^{126}$

Para Castillo Freyre, ${ }^{127}$ existirían tres causales para impugnar esta decisión:

- Cuando la decisión del tercero se haya producido incurriendo en alguno de los vicios de la voluntad del acto jurídico, vale decir: error, dolo, violencia o intimación.

${ }^{126}$ DE LA PUENTE Y LAVALLE, Manuel. El contrato de compraventa, pp. 109 y 110.

${ }^{127}$ Según este autor, en cuanto a la posibilidad de impugnación de la decisión del tercero, en la doctrina jurídica existen varias tendencias: una primera sostiene que, en principio, nunca puede impugnarse la decisión del tercero; una segunda opina que si la determinación del precio hecha por el tercero es absoluta y abiertamente inocua o injusta, simplemente deberá considerarse como que no hizo dicha determinación, es decir, que no hubo venta; una tercera sostiene que si la determinación del tercero da como resultado un precio absolutamente inocuo o desproporcionado, si bien considera que existe determinación del precio, esta puede ser impugnada judicialmente; una cuarta sostiene que la determinación del tercero sólo es impugnable si el precio resulta ser uno que configure un supuesto de lesión; una quinta sostiene que la determinación del tercero podría anularse si es que hubiese sido dada mediando vicio de voluntad; $y$, por último, una sexta señala que puede impugnarse la determinación del precio si es que el tercero ha excedido las facultades que ambos contratantes le han conferido para efectuar tal determinación (CASTILLO FREYRE, Mario. Op. cit., pp. 630 y 631). 
- Cuando la decisión del tercero excediese el ámbito del mandato recibido (es necesario precisar que para este autor nos encontramos frente a un mandato).

- En lo referente a los vicios o defectos de contenido de la decisión, vale decir, lo concerniente al monto del precio señalado para el bien, este precio podrá ser impugnado si es desproporcionado, pues al decidir las partes contratantes un arbitrio boni viri, buscan que la decisión del tercero contenga un precio justo. ${ }^{128}$

Contrariamente, Fajardo Fernández afirma:

El arbitrio de equidad de un tercero implica que el tercero tiene un ámbito de decisión tal, que impugnar su resultado es posible pero difícil. Doctrina y jurisprudencia reconocen que el arbitrio del tercero es impugnable aunque carezca de base legal, pero para admitir la impugnación sugieren criterios vagos como que la decisión del tercero sea manifiestamente contraria a la equidad, con una desproporción evidente, contraria a los elementos de hecho o las circunstancias del caso. Por mucho que se especule sobre estos $u$ otros criterios, el margen de decisión de un tercero que realiza un arbitrio de equidad es muy amplio, y su decisión resulta prácticamente imposible de impugnar con base en este apartado, como muestra el hecho que no conozco ninguna sentencia en la que el TS lo haya concedido. ${ }^{129}$

Por nuestra parte, nos aunamos a la posición de Salvat, ${ }^{130}$ Lafaille, ${ }^{131}$ León Barandiarán, ${ }^{132}$ Muñoz, ${ }^{133}$ Machado, ${ }^{134}$ Llerena, ${ }^{135}$

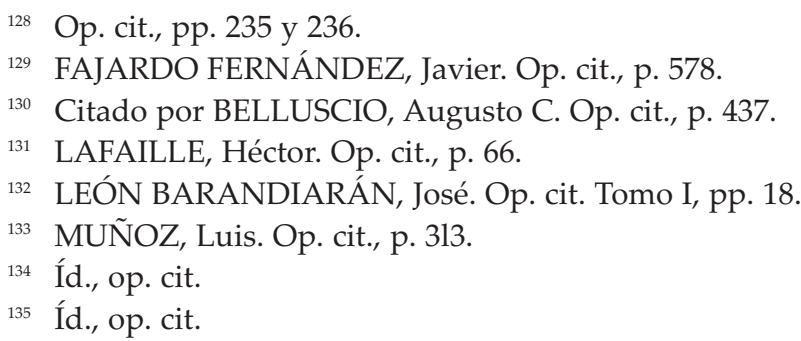


Laurent, ${ }^{136}$ Peirano ${ }^{137}$ Colin y Capitant, ${ }^{138}$ entre otros, cuando señalan que no debería existir la posibilidad de impugnar la valoración efectuada por el tercero aduciendo que se trata de un precio muy alto o muy bajo con relación al supuesto verdadero valor del bien objeto del contrato. Excepcionalmente, consideramos que debería poder impugnarse tal decisión si se demostrara que el tercero incurrió en error, dolo, o fue víctima de violencia, o bien se apartó de las bases adelantadas por las partes en el contrato. En los demás casos, lo único que podría exigirse es la fundamentación del precio que se haya fijado. Existiendo esta, el precio sería irrevocable.

Por otro lado, en cuanto a la discusión en la doctrina acerca de si el juez puede sustituir al tercero cuando su decisión haya sido impugnada por la parte que se sienta perjudicada, nos aunamos a la crítica de Castillo Freyre, ${ }^{139}$ en el sentido de que la función de los tribunales está centrada, en lo referente a los contratos, en dirimir las controversias surgidas por las partes contratantes una vez establecidos todos los elementos (esenciales, naturales y accidentales) de un contrato, y no en contribuir con ellas a la conclusión de un acto jurídico de tales características. Por esta razón, no sería adecuado sustituir la labor del tercero por un juez, aunque este fuese asesorado por peritos expertos, pues habría que considerar que las partes eligieron al tercero no solo por sus cualidades técnicas, sino también en razón de sus condiciones morales y personales.

\subsection{Aplicación del mero arbitrio}

De la Puente y Lavalle piensa que si las partes convienen expresa o tácitamente en que la determinación del precio queda librada al mero arbitrio del arbitrador, este queda liberado de actuar con arreglo a la equidad y queda sometido exclusivamente a sus apreciaciones personales, sin considerar pautas prefijadas, pero tampoco sin ofender a la lógica, pues, si no, aquello dejaría de ser arbitrio, para convertirse en un querer sin freno.

136

138

139

Íd., op. cit.

${ }_{137}$ PEIRANO FACIO, Jorge y Gustavo ORDOQUI CASTILLO. Op. cit., p. 279.

COLIN, Ambroise y Henri CAPITANT. Op. cit. Tomo II, pp. 57 y 58.

Op. cit., pp. 247 y 248. 
También precisa que la aplicación del artículo 1408 del Código Civil determina que el arbitrador deba ceñir su conducta al prototipo de conducta social media, teniendo en cuenta el contexto social en el que actúa el sujeto. De lo que se trata es de juzgar la conducta del arbitrador en lo referente a la imparcialidad y la corrección, con relación al prototipo, para acreditar si ha actuado con mala fe, entendida como la voluntaria parcialidad de la determinación a favor de uno de los contratantes. ${ }^{140}$

Díez-Picazo comenta que, frente al arbitrio de equidad, en el que el arbitrador emite su decisión ligada o vinculada a un criterio objetivo de justicia, el arbitrio simple se presenta como algo enteramente libre, sin vínculos ni ataduras. Sin embargo, afirma que por este camino se llegaría a que el arbitrador no manifestara su opinión, sino lo que quisiera, con la consecuencia de que el arbitrio se encontraría a un paso de la arbitrariedad, puesto que aquel podría decidir de una manera manifiestamente inicua. ${ }^{141}$

Por nuestra parte, conforme a la doctrina mayoritaria, consideramos que el mero arbitrio se presenta como algo enteramente libre.

Así, en el caso del precio determinado por un tercero, al ser resultado de una valorización absolutamente subjetiva, sería prácticamente imposible calificarlo de arbitrario teniendo como referente exclusivo un precio cualquiera, pues, como se ha expresado, las diversas motivaciones que impulsan la valorización que realizan los sujetos del mercado los llevará a resultados igualmente distintos. En uno u otro caso, los distintos precios que se acuerden conforme a las reglas del mercado, no podrán ser calificados como arbitrarios, pues son el producto de la libre negociación de los sujetos actuantes, quienes verán satisfechas sus necesidades al elegir la mejor alternativa que, en determinadas circunstancias, maximice la satisfacción de sus necesidades.

\subsection{Impugnación del mero arbitrio}

De acuerdo con el artículo 1408 del Código Civil, la determinación librada al mero arbitrio de un tercero no puede impugnarse si no se prueba

140 DE LA PUENTE Y LAVALLE, Manuel. El contrato de compraventa, pp. 110 y 111.

${ }_{141}$ DÍEZ-PICAZO Y PONCE DE LEÓN, Luis. Op. cit., pp. 138 y 139. 
su mala fe; ${ }^{142}$ y si falta la determinación y las partes no se ponen de acuerdo para sustituir al tercero, el contrato es nulo.

Para establecer lo que es la mala fe es preciso conocer lo que es la buena fe. A este respecto, De la Puente y Lavalle expresa:

La mayoría de la doctrina considera que la buena fe se ha plasmado legislativamente en dos sentidos, uno subjetivo y otro objetivo: en sentido subjetivo, la buena fe se refiere a la intención con que obran las personas o la creencia con que lo hacen (adquirente, poseedor, cónyuge del bígamo), por lo cual se le llama buena fe-creencia; en sentido objetivo, la buena fe actúa como regla general de conducta, que orienta la actuación leal del sujeto (negociación del contrato, cumplimiento de la relación obligatoria creada por él), lo que determina que se le llame buena fe-lealtad. ${ }^{143}$

El mismo autor comenta acerca de la impugnación del mero arbitrio:

La aplicación del artículo 1408 del Código Civil determina que el arbitrador deba actuar ciñendo su conducta al prototipo de conducta social media, teniendo en cuenta el contexto social en el que actúa el sujeto. No se trata de despersonalizar la figura del arbitrador, sino solamente de juzgar su conducta en lo que se refiere a la imparcialidad y la corrección con relación al prototipo (...).

142 Según la Enciclopedia Omeba, "En la buena fe lealtad hay una preponderancia del querer sobre el creer. Se obra leal o deslealmente porque así se quiere con pleno conocimiento de la moralidad o inmoralidad del acto. En la buena fe creencia, si bien se obra porque se quiere, se quiere porque se cree que lo obrado encaja en el ámbito de lo legalmente permitido". Asimismo, Alsina define la "buena fe probidad" como el estado ético o voluntad de obrar honestamente, y la "buena fe creencia" como el estado psicológico o creencia en el propio derecho (citado por FERNÁNDEZ CRUZ, Gastón. “La buena fe en la concurrencia sobre bienes inmuebles". Derecho 47. Lima: Facultad de Derecho de la Pontificia Universidad Católica del Perú, 1987, p. 175).

${ }_{143}$ DE LA PUENTE Y LAVALLE, Manuel. El contrato de compraventa, p. 111. 
A diferencia del arbitrador de equidad, que tendrá que buscar el precio justo, el mero arbitrador efectúa su evaluación aplicando sus gustos o preferencias, siempre que no se llegue al capricho o la arbitrariedad, o sea, respetando un prototipo de conducta social media. ${ }^{144}$

Por su parte, Castillo Freyre piensa que existirían tres causales de impugnación para esta decisión:

- Cuando existiere un vicio de la voluntad, tal como ha sido señalado para el caso del arbitrium boni viri.

- Si el tercero excediese las facultades otorgadas en el mandato.

- Cuando el monto del precio señalado por el tercero sea desproporcionado. Habrá precio desproporcionado cuando el precio que resulte, por exceso o por defecto, sea mayor a un quinto $(1 / 5)$ del justo precio. ${ }^{145}$

Respecto al elemento de la buena fe, Freyre propone que para evitar que la carga de la prueba recaiga siempre en la parte demandante, se establezca un criterio objetivo que permita presumir la existencia de la mala fe si es que el monto dinerario señalado como precio del bien superase (por exceso o por defecto) un límite con relación al justo precio, el que propone sea establecido por el Código Civil en su artículo 1448 - para invertir la carga de la prueba en la lesión - , a fin de presumir la existencia de mala fe por parte del tercero (mandatario-arbitrador-no perito). En este caso, quien debería probar la no existencia de mala fe sería el demandado, no el demandante. ${ }^{146}$

Por nuestra parte, consideramos que si el tercero no puede o no quiere determinar el precio, el contrato será resuelto por aplicación del artícu-

144 DE LA PUENTE Y LAVALLE, Manuel. El contrato en general. Volumen XI, primera parte, tomo III. Lima: Fondo Editorial de la Pontificia Universidad Católica del Perú, 1998, pp. 405 y 406.

145 CASTILLO FREYRE, Mario. Op. cit., p. 236.

${ }^{146}$ Op. cit., pp. 248 y 249. 
lo 1371 del Código Civil, desde que la inexistencia del precio es una causal sobreviniente a su celebración, salvo que las partes hayan designado desde el inicio a la persona que sustituirá en tal situación al tercero.

Con respecto a la determinación del elemento de la mala fe, pensamos que esta no debería presumirse teniendo como criterio exclusivo la desproporción entre el precio fijado por el tercero y el supuesto "precio justo", pues, tal como se ha demostrado, no existe un criterio económico ni objetivo para determinar cuál sería dicho "precio justo", que sea independiente de la verdadera voluntad de las partes contratantes en cada caso concreto.

En ese sentido, reafirmamos la posición que sostuvimos en relación con el arbitrio de equidad, cuando señalamos que no habría posibilidad de impugnar la valoración efectuada por el tercero aduciendo que se trata de un precio muy alto o muy bajo con relación al supuesto verdadero valor del bien objeto del contrato. Sin embargo, consideramos que sería posible impugnar tal decisión en el caso de que se demostrara que el tercero incurrió en error, dolo, o fue víctima de violencia, o bien se apartó de las bases adelantadas por las partes en el contrato. En otros casos, lo único que podría exigirse es la fundamentación del precio que se haya fijado. Existiendo ella, el precio sería irrevocable.

\subsection{Retroactividad de la determinación}

Se ha visto que autores como Planiol y Ripert, ${ }_{1}^{147}$ Wayar, ${ }^{148}$ entre otros, piensan que el contrato de compraventa cuyo precio debe ser fijado por un tercero es un contrato sujeto a una condición suspensiva, y que cuando esta se cumple, sus efectos se retrotraen a la época de la celebración del contrato.

$\mathrm{Al}$ respecto, De la Puente y Lavalle comenta que pese a no compartir la opinión de que la designación del tercero para que determine el precio es una condición suspensiva del contrato de compraventa, y que el artículo 177 de nuestro código dispone que la condición no opera

147 PLANIOL, Marcel y Georges RIPERT. Op. cit., p. 918.

148 WAYAR, Ernesto. Op. cit., p. 287. 
retroactivamente, salvo pacto en contrario, considera que debe otorgarse carácter retroactivo a la determinación hecha por el arbitrador. La razón sería que el contrato de compraventa queda válidamente celebrado desde el momento en que las partes están conformes con todos sus extremos, entre los cuales se encuentra el pacto sobre determinación del tercero para que determine el precio, lo que sería una modalidad de precio determinable. Lo lógico sería, entonces, que, cuando el arbitrador determine el precio, esta determinación deba tener efecto retroactivo al momento de celebrarse el contrato. ${ }^{149}$

Contrariamente, Gómez Estrada opina:

$\mathrm{Si}$, en cambio, el tercero fija el precio, según una opinión, adquiere el contrato plena existencia, no a partir del momento en que tal fijación se produce, sino desde el momento de su celebración, porque dicha fijación se entiende hecha retroactivamente, lo que tiene mucha importancia para efectos relacionados con la teoría de los riesgos en la compraventa (art. 1876). Es de advertir, sin embargo, que, como se hizo ver atrás para casos de naturaleza similar, no se trata de la estipulación de una conditio facti, sino de una conditio iuris; entendidas así las cosas el contrato apenas tendría existencia al fijarse el precio, o sea que esa fijación no tendría efecto retroactivo. ${ }^{150}$

Por otro lado, Fajardo Fernández comenta:

Los contratos con precio determinable que carecen de uno inicial se encuentran sometidos a una fase peculiar pendiente pretio, distinta de las situaciones de pendencia propias de la condición y el término, y que se puede reconstruir a partir de ellas, teniendo en cuenta que la pendencia del precio determinable está provocada por un certus an,

149 DE LA PUENTE Y LAVALLE, Manuel. El contrato de compraventa, pp. 111 y 112.

${ }^{150}$ GÓMEZ ESTRADA, César. Op. cit., p. 30. 
incertus quando, incertus quantum y no se presume establecidas a favor de ningún contratante, como más bien en perjuicio de todos ellos. Esta situación se podrá calificar como una pendencia de la obligación de pagar el precio en cuanto a sus efectos definitivos. Aparte de eso, el contrato y la misma obligación de pagar tienen una cierta exigibilidad provisional y se encuentran especialmente sometidos a las obligaciones derivadas de la buena fe; no están sometidos a pendencia la obligación de entregar la cosa ni los efectos reales que se derivan de ella; debe descartarse que el precio determinable suponga un régimen especial en cuanto a los riesgos de la cosa vendida; y no cabe instar la resolución por impago del precio mientras éste sea desconocido; pero sí por cualquier motivo. ${ }^{151}$

Por su parte, Luis Muñoz afirma: "Y es que la venta, en el supuesto que examinamos, es perfecta, válida y eficaz, pues la norma jurídica considera elemento constitutivo suficiente del negocio bilateral el precio determinable. Ahora bien, si no llega a determinarse el precio, el contrato habría de resolverse por imposibilidad sobrevenida de la prestación" ${ }^{152}$

En ese sentido, los Mazeaud explican:

Cuando el contrato contenga un precio determinado o determinable, la compraventa se perfecciona, al menos en principio (...), desde el cambio de los consentimientos del vendedor y el comprador. Ocurre así incluso cuando el precio es solamente determinable; la formación de la compraventa no se retrasa ya al día en que, por el juego de los elementos de referencia, se conozca el importe del precio.

No es porque tal compraventa se habría concluido bajo la condición suspensiva de la fijación del precio, condición que se retrotraería al día del cambio de los consentimientos. Tal análisis sería inexacto, porque

\footnotetext{
151 FAJARDO FERNÁNDEZ, Javier. Op. cit., p. 632.

152 MUÑOZ, Luis. Op. cit., pp. 306.
} 
no puede servir de condición un elemento esencial del contrato; y ese es el caso del precio.

La perfección de la compraventa en el día del cambio de los consentimientos se justifica por la existencia del precio desde ese día. Ciertamente, el importe del precio no será conocido aún; pero los elementos que permitirían fijar el importe son conocidos ya, y la voluntad de las partes no podrá ya modificarlos. El precio, aun solamente determinable, se halla establecido así desde el instante del cambio de los consentimientos; nada se opone a la perfección del contrato. ${ }^{153}$

Por nuestra parte, consideramos que la compraventa con precio determinable, al ser un contrato de efectos obligatorios, ${ }^{154}$ debería ser considerada un contrato válido, perfecto y eficaz desde el momento en que las partes contratantes expresan su consentimiento. ${ }^{155}$

Además, el hecho de que el precio sea determinable en el contrato de compraventa no quiere decir que no haya contrato ni que sus efectos estén condicionados, pues, como se ha visto, para que haya compraventa solo se requiere que en el momento en se acordó el contrato el precio sea determinable. Por eso, pensamos que resulta innecesario disponer el carácter retroactivo de la fijación del precio a cargo del tercero, pues el contrato debería surtir efectos desde el momento mismo del acuerdo de los contratantes. Si bien el monto al que ascendería el precio no puede ser conocido en ese momento, los criterios que permiten determinarlo son conocidos desde un inicio y la voluntad de las partes no podrá ya modificarlo. El precio es determinable desde la celebración del contrato, hasta el momento en que sea determinado. Por tanto, el hecho de que sea determinable en el momento de celebrar el contrato no es la causa del eventual perjuicio que pudiera sufrir cualquiera de las partes por su

${ }^{153}$ MAZEAUD, Henri, Jean y León. Op. cit., pp. 146 y 147.

154 Ver el artículo 1529 del Código Civil peruano.

155 Esta es la opinión de Enneccerus, al decir que "la compraventa es un negocio obligatorio y los efectos inmediatos de la misma son de naturaleza obligatoria". ENNECCERUS, Ludwig; KIPP, Theodor y Martin WOLF. Tratado de derecho civil. Tomo II. Barcelona, 1950, p. 14. 
posterior indeterminación. En ese orden de ideas, desde nuestra posición doctrinaria, según la cual el juez no debería suplir al arbitrador para determinar el precio, pensamos que si una de las partes se siente perjudicada por aquella indeterminación debería poder solicitar la resolución del contrato de compraventa, pues la causa que origina el perjuicio es sobrevenida a la celebración del contrato y no contemporánea al mismo. ${ }^{156}$

\section{A modo de conclusión}

Nuestra modesta reflexión acerca de la exposición realizada concluye en lo siguiente:

a) El precio revela las valorizaciones subjetivas de las partes contratantes. Si alguien pagó un precio por algo es porque lo valoriza en más de lo que pagó, y si alguien estuvo dispuesto a venderlo es porque lo valoriza en menos del precio pactado.

b) La doctrina jurídica mayoritaria considera que el precio de los bienes que se intercambian a través del contrato de compraventa tienen un valor objetivo. Sin embargo, en la doctrina económica la teoría objetiva del valor ha sido superada por la teoría subjetiva del valor, y el precio es el resultado de una apreciación absolutamente subjetiva de las partes contratantes al momento de establecer el valor de los bienes que intercambian, utilizando el dinero como medio de cambio.

c) La doctrina jurídica mayoritaria considera como segundo requisito del precio el que sea cierto, bastando para dicha certidumbre que se trate de un precio determinado o determinable. El precio determinado es aquel cuyo monto se fija expresamente en el contrato de compraventa; y el precio determinable es aquel cuyo monto, si bien no se fija expresamente en el contrato, encuentra en este, fijadas en el

156 Entonces, en el contrato de compraventa con precio determinable no deberían estar sometidos a pendencia la obligación de entregar la cosa ni los efectos reales que se derivan de ella. Así, en el caso de que el precio no pudiera ser determinad a las partes contratantes y el vendedor 
momento de su suscripción, las reglas necesarias y suficientes para que, sin la posterior intervención de las partes contratantes, se pueda determinar. Por nuestra parte, teniendo en claro que, en principio, el precio es la expresión de la subjetividad de las partes, opinamos que deberían ser éstas las únicas que puedan llegar a establecerlo. Sin embargo, si la voluntad de ellas es dejar la determinación del precio en manos de un tercero, no encontramos inconveniente en que así sea, sobre todo si se considera que ellas, por su propia voluntad, están asumiendo el riesgo de esa determinación en relación con la manera como será efectuada.

d) Por último, deseamos invitar a nuestros juristas a investigar las importantes consecuencias de este estudio, que busca contribuir en la formación de un sistema jurídico más eficiente y justo, que se muestre acorde con los avances de nuestra sociedad. 


\section{Bibliografía}

BADENES GASSET, Ramón. El contrato de compraventa. Tomo I. Buenos Aires: Librería Bosch, 1979.

BELLUSCIO, Augusto C. Código Civil y leyes complementarias. Buenos Aires: Editorial Astrea, 1988.

BIANCA C., Massimo. La vendita e la permuta. Torino: Unione Tipográfica/ Editrice Torinese, 1972.

BONNECASE, Julien. Elementos de derecho civil. Tomo II. Puebla: Biblioteca Jurídico Sociológica, 1945.

CASTILLO FREYRE, Mario. El precio en el contrato de compraventa y permuta. Lima: Fondo Editorial de la Pontificia Universidad Católica del Perú, 1996.

COLIN, Ambroise y Henri CAPITANT. Curso elemental de derecho civil. Tomo IV. Madrid: Instituto Editorial Reus, 1955.

DE LA PUENTE Y LAVALLE, Manuel. El contrato en general. Volumen XI, primera parte, tomo III. Lima: Fondo Editorial de la Pontificia Universidad Católica del Perú, 1998.

DE RUGGIERO, Roberto. Instituciones del derecho civil. Tomo II, volumen II. Madrid: Instituto Editorial Reus, 1944.

DÍEZ-PICAZO, Luis. La representación en el derecho privado. Madrid: Editorial Civitas S.A., 1979.

DÍEZ-PICAZO, Luis y otro. Sistema de derecho civil. 2. ${ }^{a}$ edición. Volumen II. Madrid: Editorial Temis, 1980.

ESPÍN, Diego. Manual de derecho civil español. Volumen VIII. Madrid: Editorial Revista de Derecho Privado, 1983.

ETCHEVERRY, Raúl Aníbal. Derecho comercial y económico (Contratos). Parte especial I. Buenos Aires: Editorial Astrea, 1991.

GASCA, C.L. Compraventa civil y comercial. Tomo I. Madrid: Revista de Derecho Privado, 1931.

GÓMEZ ESTRADA, César. De los principales contratos. 3. ${ }^{a}$ edición. Bogotá: Editorial Temis S.A., 1996.

LAFAILLE, Héctor. Curso de contratos. Tomo II. Buenos Aires: Biblioteca Jurídica Argentina, 1928. 
LEÓN BARANDIARÁN, José. Contratos en el derecho civil peruano. Tomo I. Lima: Universidad Nacional Mayor de San Marcos, 1965.

LETE DEL RÍO, José M. Derecho de obligaciones. Madrid: Editorial Tecnos S.A., 1990.

MAZEAUD, Henri, León y Jean. Tratado de derecho civil. Parte III, volumen III. Buenos Aires: Ediciones Jurídicas Europa-América, 1959.

MUÑOZ, Luis. Contratos. Tomo II. Buenos Aires: Tipográfica Editora Argentina, 1960.

OSPINA FERNÁNDEZ, Guillermo y Eduardo OSPINA ACOSTA. Teoría general del contrato y de los demás negocios jurídicos. Santa Fe de Bogotá: Editorial Temis S.A., 1994.

PLANIOL, Marcel y Georges RIPERT. Compendio de derecho civil. México D.F.: Editorial Pedagogía Americana, 1996.

REZZÓNICO, Luis María. Estudio de contratos en nuestro derecho civil. Buenos Aires: Ediciones Depalma, 1967.

SPOTA, Alberto G. Contratos. Volumen IV. Buenos Aires: Ediciones Depalma, 1980.

TRINCAVELLI, Nélida E. La compraventa en Roma. Buenos Aires: Lerner Editores, 1970.

WAYAR, Ernesto. Compraventa y permuta. Buenos Aires: Editorial Astrea, 1984. 